\title{
Assessment of Agricultural Drought using MODIS NDVI based Vegetation Status for Different Agro Climatic Zones of Tamil Nadu
}

\author{
S. Venkadesh ${ }^{1} *$, S. Pazhanivelan ${ }^{2}$, K.P. Ragunath ${ }^{2}$, R. Kumaraperumal ${ }^{2}$, \\ S. Panneerselvam ${ }^{1}$ and R. Sathy ${ }^{3}$ \\ ${ }^{1}$ Agro Climate Research Centre, TNAU, Coimbatore, Tamil Nadu, India \\ ${ }^{2}$ Department of Remote Sensing \& GIS, ${ }^{2}$ Department of Physical Science and IT, \\ TNAU, Coimbatore, Tamil Nadu, India \\ *Corresponding author
}

\begin{abstract}
A B S T R A C T

\begin{tabular}{|l|}
\hline Ke y w or d s \\
MODIS NDVI, \\
Drought \\
assessment, \\
Vegetation and \\
NEM
\end{tabular}

Drought is a complex natural phenomenon and its impact on agriculture is enormous. The vegetation status was verified using MODIS satellite images through the Normalized Differential Vegetation Index (NDVI) for different agro-climatic zones (ACZ) over Tamil Nadu during the north-east monsoon season of 2015 (as extremely wet year), 2016 (as drought year) and 2017 (as normal year) for our analysis and it showed that satellite data was very effective for assessing the agricultural drought. From this analysis it was found that there is no much variation in the area obtained by the NDVI for that year of 2015 where $34.9 \%$ stressed area in the north eastern zones. It is believed that the increased status of NDVI over these seasons is due to the extreme rain in this year. The stressed area was more prominent over the north eastern zone $(48.3 \%)$ in the year of 2016 and also second highest stressed area among the seasons because of the drought year. While in the year 2017 it was found that 49.9 per cent area was stressed in western zone and highest stressed area among the different zones. Therefore, the vegetation status was high during the year of 2015 compared to the remaining years of season.
\end{abstract}

\section{Introduction}

Drought is a natural phenomenon that has a significant impact on a social, economic and environmental sphere. The concept of drought often varies between regions with different climates. In addition, the drought gives an impression of water scarcity resulting from insufficient precipitation, high evapotranspiration, and over-exploitation of water resources or a combination of these parameters (Bhuiyan, 2004). According to the operational definition, there are four types of drought; meteorological drought, agricultural drought, hydrological drought, and socioeconomic drought are all related to each other (Dogondaji and Muhammed, 2014). When the actual precipitation is significantly lower than the normal level (meteorological drought), it leads to an obvious depletion of 
groundwater and surface water levels (hydrological drought), which in turn causes soil drying and severe crop stress (agricultural drought). Precise spatial analysis of meteorological severity level of drought requires a dense network of rain gauge stations. But the availability of weather data is developed in many regions whereas spatiotemporal analysis of agricultural drought can be effectively done with advances in the fields of satellite remote sensing and geographic information systems (GIS) (Shaw and Krishnamurthy, 2009). Agricultural drought is usually monitored using satellite sensors to detect vegetation indices and surface temperature. Among the various vegetation indices, NDVI (Normalized Difference Vegetation Index) is widely used as a proxy for the assessment in operational drought (Pettorelli et al., 2005; Panda et al., 2010). Water has negative NDVI, whereas the clouds and barren lands have zero NDVI. Vegetation always has positive NDVI actually representing the density, vigor and higher index values associated with greater green leaf area and biomass.

Remote Sensing (RS) innovation is broadly utilized in natural and agricultural sciences. The NDVI, a standout amongst the most notable vegetation images acquired from optical RS products, has been widely used to appraise plant biomass and vegetation. Moderate Resolution Imaging Spectroradiometer (MODIS) is the essential sensor for checking the terrestrial biological system in the Earth Observing System (EOS) program of NASA (National Aeronautics and Space Administration) (Thenkabail et al., 2004).

Gumma et al., (2012) reveals that to outline territories in Odisha from 2000-01 to 2010-11 utilizing MODIS 250m 8-day time serious data with spectral matching techniques and identify stress-prone rice areas inclined rice region in the state. This investigation shows that utilization of MODIS time series data in monitoring rice areas including cropping pattern and cropping intensities across stress prone areas. Rama Krishnan et al., (2015) concentrated on Geospatial approach for surveying and observing the dry season condition in Chittur taluk Palakkad area Kerala. They were utilized Landsat 5 (ETM+) information. For the examination, they are predominantly moved in various vegetation and soil lists for portraying dry season state of Chittur Taluk. The dry season appraisal completely dependent on NDVI, MSI, YVI, VCI, and SPI of the zone. The investigation inferred that 2014 need to influence extreme dry season condition in Chittur Taluk, it exceptionally influenced in the regular asset of the region.

Tamil Nadu State has experienced frequent droughts in recent past, leading in serious distress for the agriculture society. In order to demonstrate spatial pattern of vegetation conditions a wet, drought and normal years were chosen and evaluated from the index and then categorized based on vegetative growth levels. This research focuses on the assessment of agricultural drought over Tamil Nadu by analyzing vegetation condition using NDVI multi-temporal data obtained from MODIS during the northeast monsoon season from October 2015 to December 2017 in various agro-climatic zones (ACZ).

\section{Study area}

Tamil Nadu state which is situated in the south-eastern part of the India and is shown in Figure 1. The geographical extent of the state lies between $08^{\circ} 00^{\prime} \mathrm{N}$ to and $13^{\circ} 30^{\prime} \mathrm{N}$ latitudes and $76^{\circ} 15^{\prime} \mathrm{E}$ and $80^{\circ} 18^{\prime} \mathrm{E}$ longitudes. The total area of Tamil Nadu reaches out to $1,30,058 \mathrm{~km}^{2}$. Tamil Nadu is the state in India where rain fed agriculture is 
the predominant occupation. Based on climatic conditions and farming produce, Tamil Nadu is partitioned into seven agroclimatic zones: northeastern, northwestern, cauvery delta, western, high-alititude, southern and high rainfall zones. The state is given with two significant monsoon which contribute precipitation to the state. They are: Southwest monsoon from June to September and Northeast monsoon from October to December.

At the point when every other parts of India gets more precipitation amid the southwest monsoon, Tamil Nadu gets rainfall only during northeast monsoon. The annual precipitation of the state was observed to be $911.6 \mathrm{~mm}$. Northeast monsoon contributes 47 percent of complete annual precipitation while the southwest monsoon contributes 35 percent of total rainfall (Indira et al., 2013). As in excess of 80 percent of the state relies upon precipitation for their seasonal crop production, it is more prone to agricultural drought whenever monsoon fails. The significant crops of State are paddy, maize, banana, sugarcane, cotton, groundnut and vegetables.

\section{Remote sensing based vegetation indice}

\section{Normalized difference vegetation index}

Normalized Difference Vegetation Index (NDVI) depends on the possibility of vegetation quality and its sign of water nearness or non-attendance. It enables us to examine the impact of the climatic condition on the vegetation in a zone as far as the absorptive capacity in the visible band and the near-infrared band (Rouse et al., 1973). The difference of visible and near-infrared reflectance represents photosynthetically effects and the lively vegetation, this will be useful in building the vegetation record.
$N D V I=\frac{N I R-R E D}{N I R+R E D}$

where, NIR and RED are the reflectance in the near-infrared and red bands, respectively. The NDVI is the most usually utilized vegetation index, it varies in a range of - 1 to +1 . The lower value in the vegetation index indicates wetness stress in the vegetation, because of delayed precipitation inadequacy. The higher NDVI values demonstrate the perfect climatic condition for crop growing condition and that shows the vegetation is higher (Myneni et al., 1995).

\section{Modis data collection}

NDVI derived from MODIS onboard is utilized for observing vegetation growth and health. The primary source of satellite information which has been utilized is Moderate Resolution Imaging Spectroradiometer (MODIS) data products. In this investigation, a 16-day composite MOD13A1 data from MODIS/Land Vegetation indices at $500 \mathrm{~m}$ resolution have been collected for a NEM period of three years (2015-2017) since 2015 (as extremely wet year), 2016 (a drought year) and 2017 (as normal year) for our analysis because the chief rainy season for Tamil Nadu with $48 \%(438.2 \mathrm{~mm})$ of its annual precipitation during this season. The study area covered in 2 tiles (h25v07 and h25v08) was obtained and this information canfreely downloaded from earth data web site (http://search.earthdata.nasa.gov).

\section{Pre-processing of satellite data}

The MODIS NDVI data is accessible in the Hierarchical Data Format (HDF) format. Before utilizing MODIS data, tiles were merged, mosaicked, subsetted and reprojected to WGS 84 Transverse Mercator, which is the regularly utilized projection framework in the Indian situation. The 
MODIS reprojection tool was utilized and the projection was developed. These re-projected images were re-scaled to retain the NDVI value ranging from -1 to +1 utilizing the scale factor 0.001 .

\section{Materials and Methods}

For various ACZs over Tamil Nadu, the NDVI method was conducted. For three years (October-December) of the NEM period, the seasonal average NDVI of all pixels in different ACZ was obtained from the masked NDVI images. NDVI can be used as a vegetative drought index to evaluate crop condition by analyzing NDVI composites. In order to obtain seasonal NDVI average in each year, maximum value composites (MVC) of NDVI images were computed for each season (Goward et al., 1994). Raster calculator was used to generating seasonal NDVI average, which was produced using ArcGIS 10.1 software. The NDVI percentage of the area was then obtained for each pixel for different ACZ of Tamil Nadu, which can conduct it using the maximum value composite methods that maintained only the greater pixel value of these multiple data. It is only relevant when there is a series of multiple data for a single year with a distinct month.

The NDVI images for a given pixel always lead in a number ranging from minus one (-1) to plus one $(+1)$; however, the vegetation status of the agro-climatic zone has been categorized as shown below. The NDVI extracted from MODIS data, seasonal NDVI development and time series NDVI profiles were used to assess the agricultural drought in agro-climatic zones of Tamil Nadu.

The NEM season was chosen to explore the spatial and seasonal NDVI. The NDVI value for these classes was obtained from the approach proposed by Tucker, 1979. The range of NDVI values acquired and the five classifications were regarded viz., $<0,0.0-0.2$, $0.2-0.4,0.4-0.6$ and $>0.6$. After defining the categories, we excluded no vegetation and barren classes because reflectivity is either very low or zero to identify vegetation pattern. Finally, the regions under no vegetation, barren, stressed, good and very good condition have been categorized. Very good vegetation showed high value in the NDVI, and the non-vegetation areas showed negative value and were also clearly identified.

\section{Results and Discussion}

The spatial pattern of change in the average NDVI value for the year 2015 as an extremely rainy year indicating a higher NDVI value and displaying the very good vegetation cover over the whole area. Very good vegetation status was shown in high altitude hilly zone and high rainfall zone and some parts of the Cauvery delta zone covered normal vegetation situation. Vegetation status improved in 2015 as severity vegetation decreased. It is well illustrated in Figure 2A. In the southern zone, the major area was in good vegetation. The western, NEZ, and CDZ display moderate vegetation conditions with small patches of remaining portions.

2016 was one of the worst years of drought in Tamil Nadu. The areas of the Western Zone, North Western Zone, Southern Zone and North Eastern Zone showed very low vegetation status and some areas showed normal vegetation status in Cauvery delta zone during 2016 (Figure 2B). The precipitation variations had a much greater impact on the vegetation pattern and had an effect on the yield of crop.

In Tamil Nadu, 2017 was a normal year. The vegetation condition indicated very moderate vegetation conditions in parts of high altitude 
and high rainfall zone. However, only a few areas of the Southern Zone, Western Zone had the very low vegetation condition as shown in Figures 2C and all remaining zones showed normal status in the ordinary year.

The assessment was carried out to assess the health area of vegetation by calculating the NDVI images values for Tamil Nadu, seasonal NDVI image were produced. For seven ACZs, the percentage of area for each classification was obtained from these images. The percentage of area has been extracted by masking classes in the study area and based on seasonal average NDVI value for different vegetation categories namely, no vegetation, barren, stressed, good and very good area was calculated for NEM only for selected years. In fact, the seasonal variations of the vegetation status were calculated from 2015 to 2017. The bar graph was also been drawn and shown in Figure 3A, 3B and 3C. The percentage area covered by each category under seven ACZ is shown in Figure 3A. The NDVI can be a precise representation of continental land cover, vegetation classification and soil phonology (Tarpley et $a l .$, 1984). The percentage of area has further changed to hectares.

Table.1 Agro-climatic zone wise area (ha) covered under NDVI vegetation of 2015

\begin{tabular}{|l|l|l|l|l|c|c|c|}
\hline Classification / Zones & \multicolumn{1}{|c|}{ SZ } & \multicolumn{1}{|c|}{ NEZ } & \multicolumn{1}{c|}{ HRZ } & CDZ & WZ & HAZ & NWZ \\
\hline No Vegetation & 20,600 & 12,575 & 2,675 & 45,025 & 3,200 & 3,475 & 1,000 \\
\hline Barren & $1,45,850$ & $2,34,750$ & 700 & 95,700 & 26,550 & 27,275 & 12,575 \\
\hline Stressed & $9,18,275$ & $11,87,850$ & 4,225 & $3,49,525$ & $3,12,775$ & $1,76,300$ & $2,03,800$ \\
\hline Good & $20,44,975$ & $13,67,700$ & 29,075 & $7,58,525$ & $8,58,925$ & $5,30,725$ & $8,70,775$ \\
\hline Very Good & $10,47,825$ & $5,99,750$ & $1,34,425$ & $9,67,800$ & $3,18,925$ & $13,72,575$ & $5,70,125$ \\
\hline
\end{tabular}

Table.2 Agro-climatic zone wise area (ha) covered under NDVI vegetation of 2016

\begin{tabular}{|l|l|l|l|l|l|l|l|}
\hline $\begin{array}{c}\text { Classification/ } \\
\text { Zones }\end{array}$ & \multicolumn{1}{|c|}{ SZ } & \multicolumn{1}{|c|}{ NEZ } & \multicolumn{1}{|c|}{ HRZ } & \multicolumn{1}{|c|}{ CDZ } & \multicolumn{1}{|c|}{ WZ } & \multicolumn{1}{|c|}{ HAZ } & NWZ \\
\hline No Vegetation & 31,225 & 15,350 & 2,500 & 50,525 & 32,075 & 5,250 & 4,325 \\
\hline Barren & $16,25,250$ & $7,03,800$ & 6,325 & $5,26,900$ & $8,78,875$ & $4,56,075$ & $6,70,725$ \\
\hline Stressed & $15,37,325$ & $16,44,400$ & 24,750 & $5,88,850$ & $3,87,150$ & $4,41,675$ & $5,38,275$ \\
\hline Good & $6,81,700$ & $7,34,125$ & 36,525 & $5,64,875$ & $1,59,575$ & $4,81,325$ & $2,56,275$ \\
\hline Very Good & $3,02,025$ & $3,04,975$ & $1,01,000$ & $4,85,425$ & 62,700 & $7,25,975$ & $1,88,675$ \\
\hline
\end{tabular}

Table.3 Agro-climatic zone wise area (ha) covered under NDVI vegetation of 2017

\begin{tabular}{|l|l|l|l|l|l|l|l|}
\hline $\begin{array}{l}\text { Classification/ } \\
\text { Zones }\end{array}$ & SZ & NEZ & HRZ & CDZ & WZ & HAZ & NWZ \\
\hline No Vegetation & 25,925 & 11,725 & 2,625 & 52,575 & 3,650 & 4,425 & 800 \\
\hline Barren & $7,86,125$ & $1,20,525$ & 10,025 & $1,05,900$ & $1,24,625$ & 61,425 & 17,800 \\
\hline Stressed & $15,80,100$ & $7,06,400$ & 23,750 & $4,22,925$ & $7,58,500$ & $3,32,175$ & $3,02,025$ \\
\hline Good & $13,23,475$ & $17,91,175$ & 41,500 & $9,72,700$ & $5,00,125$ & $5,48,750$ & $7,58,600$ \\
\hline Very Good & $4,61,900$ & $7,72,825$ & 93,200 & $6,62,425$ & $1,33,475$ & $11,63,575$ & $5,79,050$ \\
\hline
\end{tabular}


Figure.1 Study area with different agro-climate zones of Tamil Nadu

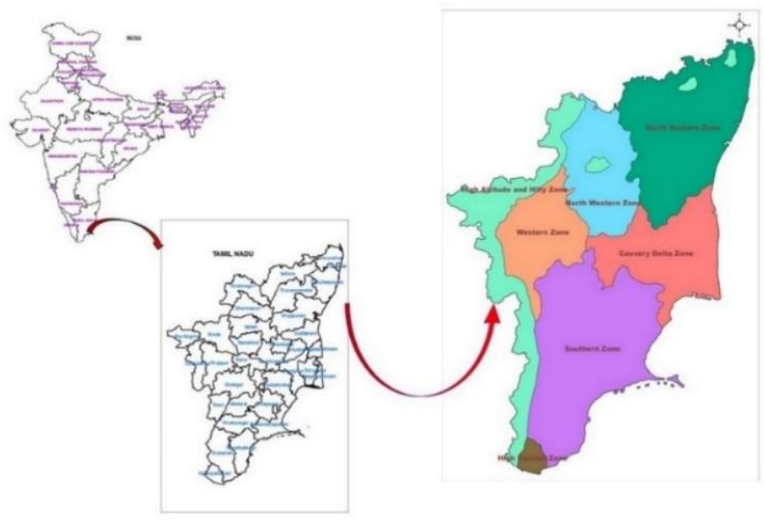

Figure.2A-C Vegetation status for agro-climatic zones of Tamil Nadu for NEM of 2015-2017
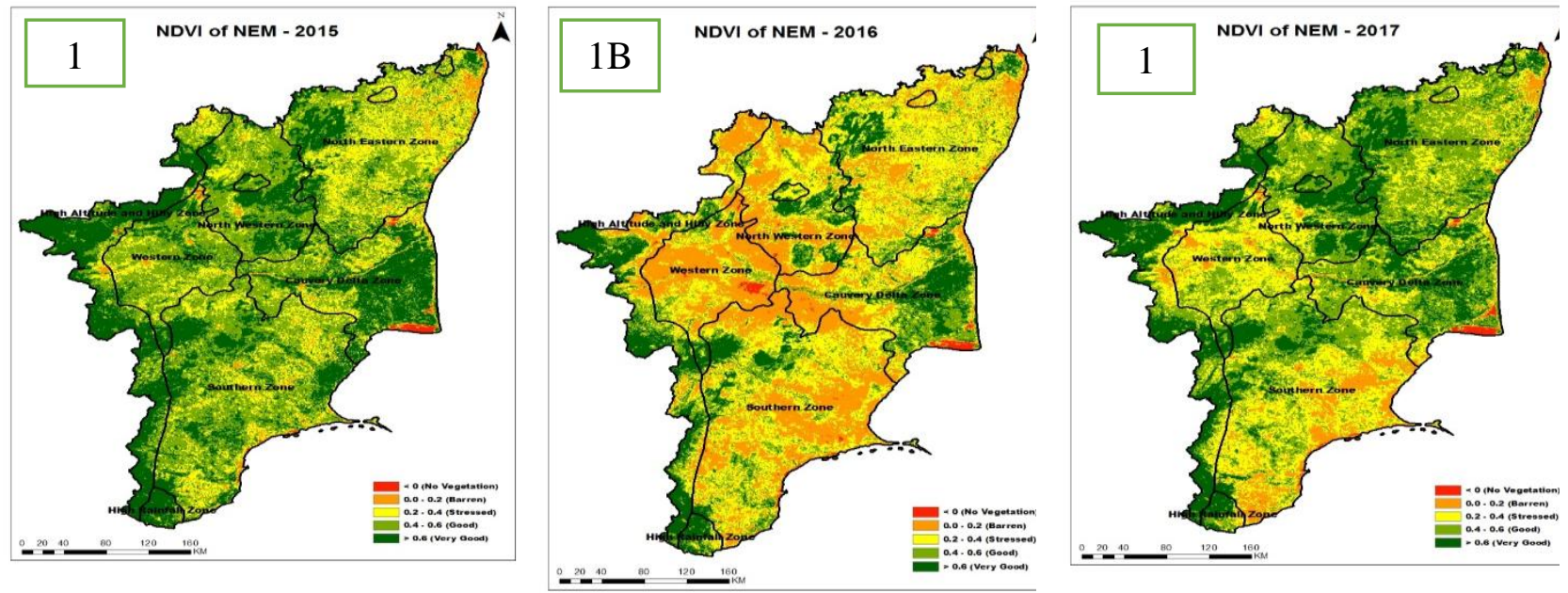

Figure.3A Percentage of the area falling under each category of vegetation pattern based on NDVI during the year 2015

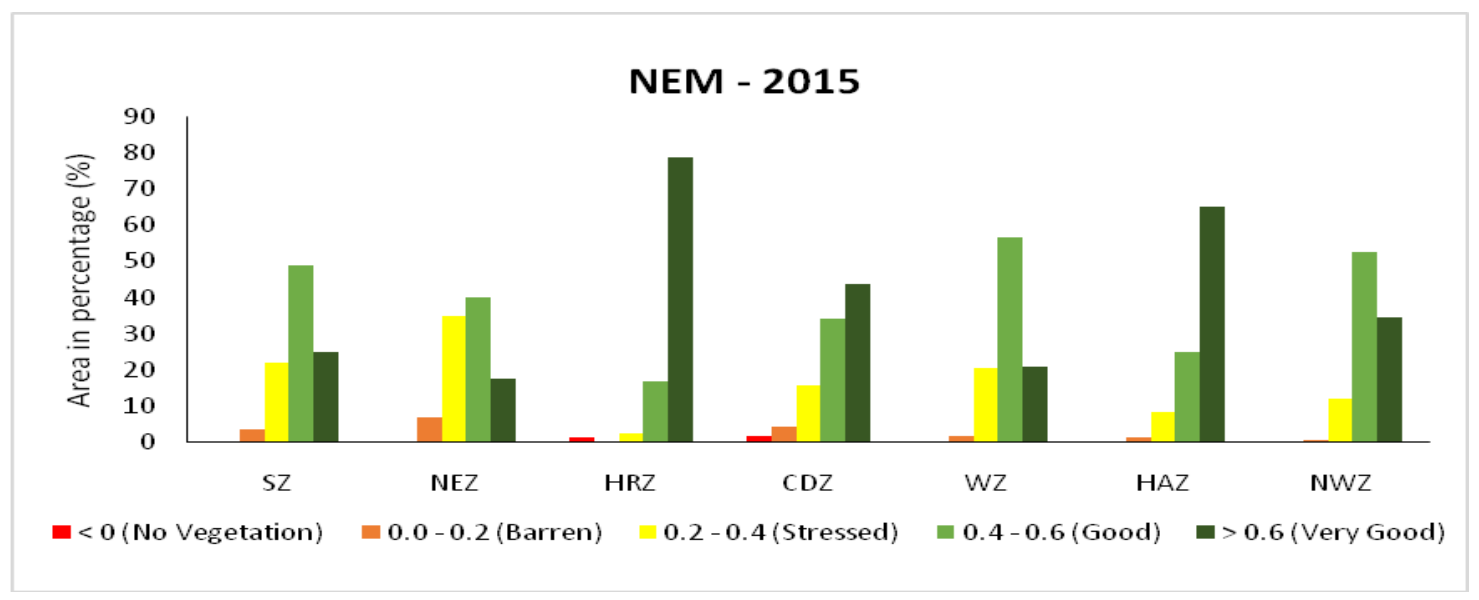


Figure.3B Percentage of the area falling under each category of vegetation pattern based on NDVI during the year 2016

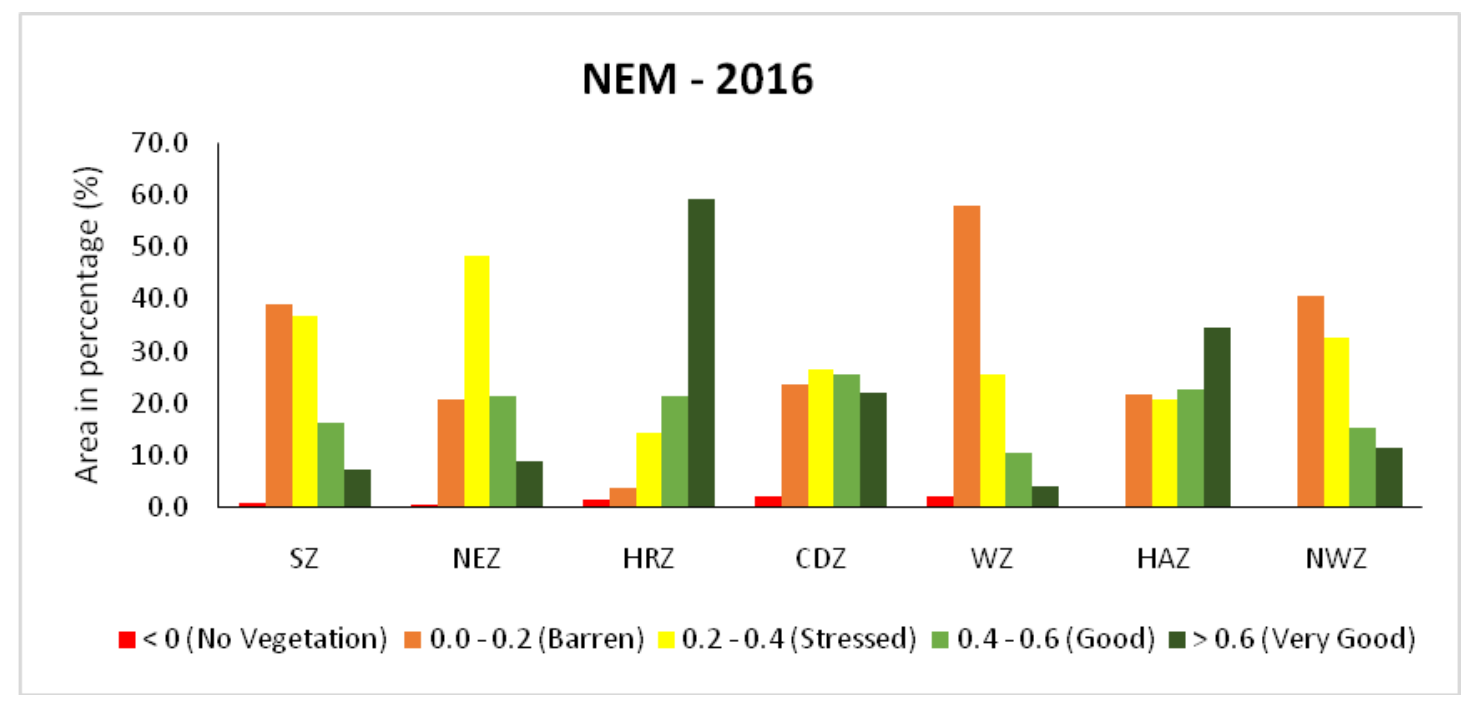

Figure.3C Percentage of the area falling under each category of vegetation pattern in the study area based on NDVI during the year 2017

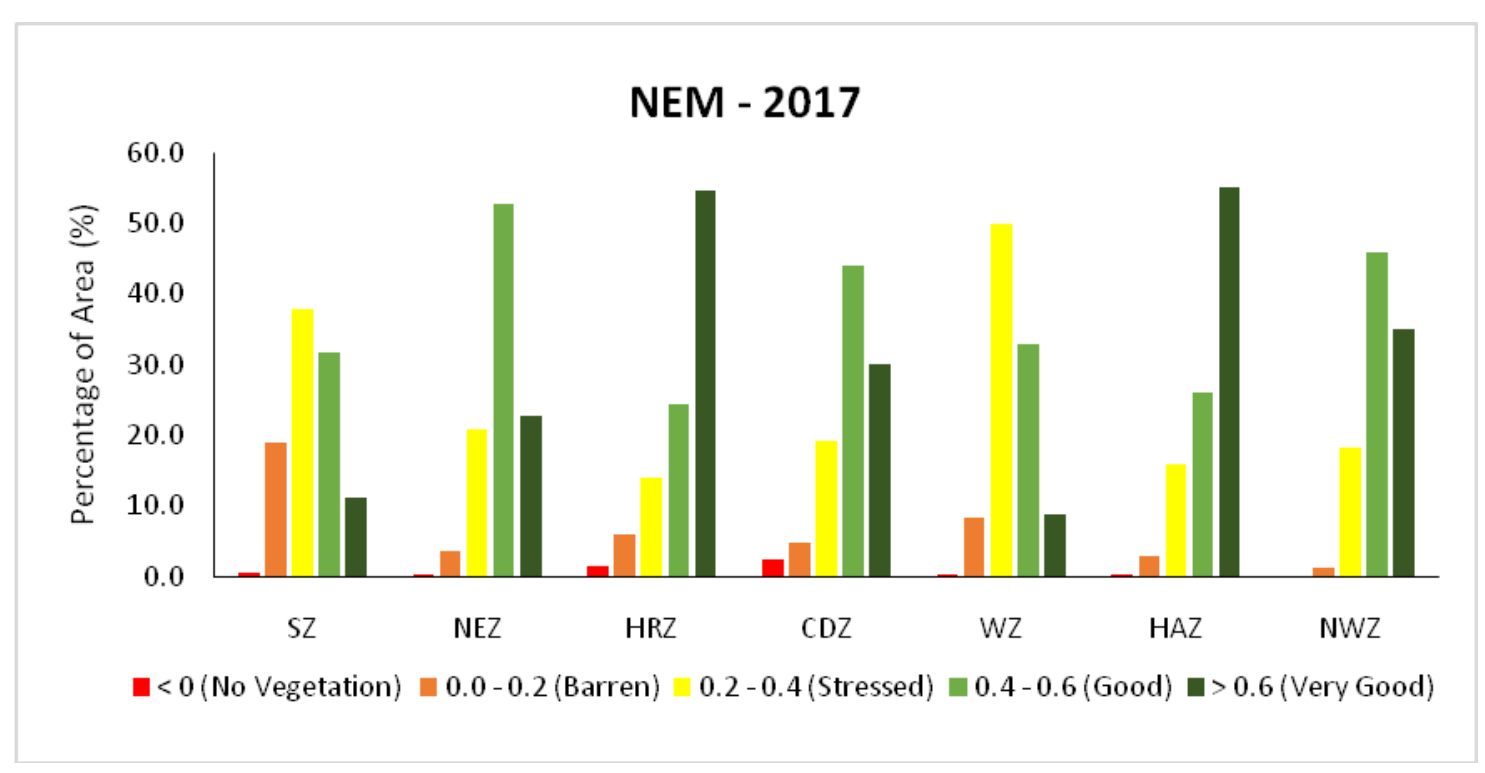

From this, in terms of percentage distribution of the vegetation area within Tamil Nadu, the northeastern zone has the highest stressed condition of 34.9 percent compared to 22.0 and 20.6 percent of the southern zone and western zone share of the area in 2015, whereas 78.6 and 56.5 percent were discovered to be in the groups of very good and good conditions due to the high amount of rainfall Figure 3A. The stressed area rises from the southern zone to the northeastern zone and then reduces in rest of the zones.

While in 2016 more area was under stressed condition increasing in all agro-climatic zones due to precipitation surplus and more area is impacted with small drought situation i.e. 48.3 percent in NEZ, 36.8 percent in the 
southern zone and 32.5 percent in the northwestern zone. In addition, only 14.5 percent was discovered to least stressed vegetation condition in the high rainfall zone through NDVI values in Figure 3B.

During 2017, the area under stress is less compared to 2016. In general, it has been observed that the western zone of 2017 represents 49.9 percent area under stressed condition due to the less average NDVI compare to the rest of the agro climatic zones (Figure 3C). Although the year 2017 was not a drought year still the stress indicates. Only 37.8 percent in the southern zone and 20.8 percent area in high rainfall zone was falling under slight and normal vegetation condition.

The agricultural drought patterns in the NEM, the vegetation status through the NDVI were verified using MODIS satellite images. Among the seven agro-climatic zones of Tamil Nadu, the North Eastern Zone has the highest stressed area of 11, 87,850 ha, followed by the Southern Zone $(9,18,275 \mathrm{ha})$ and the lowest in the high rainfall zone of 4,225 ha. Whereas $13,72,575$ and 20,44,975 ha of area under high altitude and southern zone were good and very good vegetation patterns in 2015 (Table 1).

The year 2016 recorded one of the significant droughts and the vegetation patterns in the agro-climatic zones showed stressed conditions in Tamil Nadu. It was worst affected by the failure of the monsoon Table 2. The north-eastern zone covers approximately $16,44,400$ ha of area in the stressed condition and has been found to be extremely stressed throughout the region.

The vegetative pattern in different agroclimatic zones during 2017 indicated in Table 3 , that very good vegetation conditions existed in the high-altitude zone of $11,63,575$ ha area and there was a gradual rise in vegetation vigor to good growth of green condition in the north-eastern zone with a very good vegetation condition of 7.72.825 ha. Although the high rainfall zone has less stressed (23,750 ha) and high (15,80,100 ha) in southern zone compared to other zones.

In conclusion, agricultural drought analysis has been carried out through analyzing the Normalized Differential Vegetation Index (NDVI) to assess the seasonal variability of vegetation status. The NDVI images understood for stress conditions of the area was varied from year to year. From this analysis it was found that there is no much variation in the area obtained by the NDVI for that year of 2015 where $34.9 \%$ stressed area in the north eastern zones. It is believed that the increased status of NDVI over these seasons is due to the extreme rain in this year. The stressed area was more prominent over the north eastern zone $(48.3 \%)$ in the year of 2016 and also second highest stressed area among the seasons because of the drought year. While in the year 2017 it was found that 49.9 per cent area was stressed in western zone and highest stressed area among the different zones. Therefore, the vegetation status was high during the year of 2015compared to the remaining years of season.

\section{References}

Bhuiyan, C. 2004. Various drought indices for monitoring drought condition in Aravalli terrain of India. In XXth ISPRS Congress, Istanbul, Turkey (pp. 12-23).

Dogondaji, M. B., and Muhammed, A. 2014. Analysis of meteorological drought in Sokoto State for the past four decades (1970-2009). International Letters of Natural Sciences. 15(1).

Goward, S., Y. Xue, and K. Czajkowski. 2002. "Evaluating Land Surface 
Moisture Conditions from the Remotely Sensed Temperature/Vegetation Index Measurements: An Exploration with the Simplified Simple Biosphere Model. Remote Sensing of Environment. 79: 225-242.

Gumma, M. K, Andrew, N., Thenkabail, P.S. and A.N.Singh. 2011. Mapping rice areas in South Asia using MODIS multi temporal data. Journal of Applied Remote Sensing. Vol 5, 053547.

Indira, P., Stephen, S., and Inbanathan, K. 2013. Studies on the trend and chaotic behaviour of Tamil Nadu rainfall. Journal of Indian Geophysical Union. 17(4), 335-339.

Krishnan, N. R. 2016. A Geospatial Approach for Assessing and Monitoring the Drought Condition in Chittur Taluk, Palakkad District, Kerala. International Journal of Research. 3(9), 75-85.

Myneni, R. B., Hall, F. G., Sellers, P. J., and Marshak, A. L. 1995. The interpretation of spectral vegetation indexes. IEEE Transactions on Geoscience and Remote Sensing, 33(2), 481-486.

Panda, S. S., Ames, D. P., and Panigrahi, S.2010. Application of vegetation indices for agricultural crop yield prediction using neural network techniques. Remote Sensing, 2(3), 673696.

Pettorelli, N., Vik, J. O., Mysterud, A.,
Gaillard, J. M., Tucker, C. J., and Stenseth, N. C. 2005. Using the satellite-derived NDVI to assess ecological responses to environmental change. Trends in ecology \& evolution, 20(9), 503-510.

Rouse, J.W., R.H. Hass, J.A. Schell, and D.W. Deering, 1973. Monitoring vegetation systems in the Great Plains with ERTS, NASA. Goddard Space Flight Center 3d ERTS-1 Symp., Vol. 1, Sect. A, pp 309-317

Shaw, R. and R.R. Krishnamurthy. 2009. Disaster Management: Global challenges and local solutions. Hyderabad: Universities Press (India)

Tarpley, J. D., Schneider, S. R., and Money, R. L. 1984. Global vegetation indices from the NOAA-7 meteorological satellite. Journal of Climate and Applied Meteorology, 23(3), 491-494.

Thenkabail, P. S., Enclona, E. A., Ashton, M. S., and Van Der Meer, B. 2004. Accuracy assessments of hyperspectral waveband performance for vegetation analysis applications. Remote sensing of environment, 91(3-4), 354-376.

Tucker, C.J. 1979. Red and photographic infrared linear combinations for monitoring vegetation. RemoteSens. Environ., 8, 127-150.

\section{How to cite this article:}

Venkadesh, S., S. Pazhanivelan, K.P. Ragunath, R. Kumaraperumal, S. Panneerselvam and Sathy, R. 2019. Assessment of Agricultural Drought using MODIS NDVI based Vegetation Status for Different Agro Climatic Zones of Tamil Nadu. Int.J.Curr.Microbiol.App.Sci. 8(05): 2204-2212. doi: https://doi.org/10.20546/ijcmas.2019.805.260 